\title{
The Impact of Classroom Instruction on Cultural Awareness and Sensitivity in Occupational Therapy Students
}

\author{
Sierra Grady \\ Creighton University \\ Kym Brungardt \\ Creighton University \\ Joy Doll \\ Creighton University
}

Follow this and additional works at: https://encompass.eku.edu/jote

Part of the Occupational Therapy Commons

\section{Recommended Citation}

Grady, S., Brungardt, K., \& Doll, J. (2018). The Impact of Classroom Instruction on Cultural Awareness and Sensitivity in Occupational Therapy Students. Journal of Occupational Therapy Education, 2 (2). https://doi.org/10.26681/jote.2018.020201

This Original Research is brought to you for free and open access by Encompass. It has been accepted for inclusion in Journal of Occupational Therapy Education by an authorized editor of Encompass. For more information, please contact Linda.Sizemore@eku.edu. 


\title{
The Impact of Classroom Instruction on Cultural Awareness and Sensitivity in Occupational Therapy Students
}

\begin{abstract}
As the population in the United States increases, it is essential that occupational therapy students and practitioners be aware of, respond to, and effectively interact with clients from diverse cultural backgrounds. Current literature identifies a gap in the cultural competence education for occupational therapy students and has demonstrated the importance of developing a culturally sensitive curriculum that will prepare students for today's work environment. This study employed a quasi-experimental approach with a one group pretestposttest design to explore the development of cultural awareness in occupational therapy students with classroom instruction on culturally sensitive practice. Data was collected from 43 students enrolled in an entry-level master occupational therapy program using the Cultural Awareness and Sensitivity Questionnaire (CASQ) as an online survey. Results indicated a change in the level of students' cultural awareness and sensitivity following classroom instruction. This provides evidence in the growing body of literature on the effective education of cultural competency with occupational therapy students.
\end{abstract}

\section{Keywords}

Cultural competence, education, teaching methods

\section{Creative Commons License} (c) (1) (9)

This work is licensed under a Creative Commons Attribution-Noncommercial-No Derivative Works 4.0 License.

\section{Acknowledgements}

The authors would like to acknowledge the students and faculty at Rockhurst University for their participation in this study. The authors would like to thank Vanessa Jewell, PhD, OTR/L; Surya Shah, PhD, OTR/L, FAOTA; and Liz Zayat, MS, OTR/L for their contributions to the development and implementation of this study. 


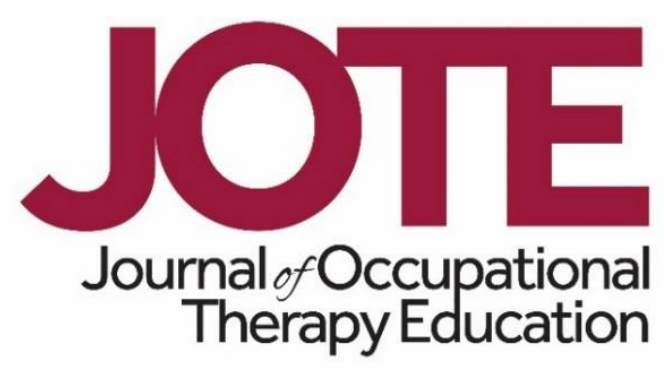

Volume 2, Issue 2

\title{
The Impact of Classroom Instruction on Cultural Awareness and Sensitivity in Occupational Therapy Students
}

\author{
Sierra Grady, MOT, OTR/L ${ }^{1,2}$, Kym Brungardt, BS, OTR/L, CLT-LANA, CHT ${ }^{1,2}$, \\ and Joy Doll, OTD, OTR/L ${ }^{1}$ \\ Creighton University ${ }^{1}$ and Rockhurst University ${ }^{2}$ \\ United States
}

\begin{abstract}
As the population in the United States increases, it is essential that occupational therapy students and practitioners be aware of, respond to, and effectively interact with clients from diverse cultural backgrounds. Current literature identifies a gap in the cultural competence education for occupational therapy students and has demonstrated the importance of developing a culturally sensitive curriculum that will prepare students for today's work environment. This study employed a quasi-experimental approach with a one group pretest-posttest design to explore the development of cultural awareness in occupational therapy students with classroom instruction on culturally sensitive practice. Data was collected from 43 students enrolled in an entry-level master occupational therapy program using the Cultural Awareness and Sensitivity Questionnaire (CASQ) as an online survey. Results indicated a change in the level of students' cultural awareness and sensitivity following classroom instruction. This provides evidence in the growing body of literature on the effective education of cultural competency with occupational therapy students.

INTRODUCTION

Occupational therapy practitioners live and work in a multicultural society. In the next 50 to 75 years, the majority of the population of the United States will be made up of individuals with diverse cultural backgrounds (Humbert, Burket, Deveney, \& Kennedy, 2012; Murden et al., 2008). As the multicultural population of the United States increases, all health care providers must effectively interact with clients from culturally diverse settings (Masin, 2011). Cultural awareness and the development of cultural competency is vital to effective occupational therapy practice and providing services to these diverse populations (Kale \& Hong, 2007; Mu, Coppard, Bracciano, Doll, \&
\end{abstract}


Matthews, 2010). Occupational therapy practitioners must be aware of and respond to cultural differences that influence clients' occupational performance, assessments, and intervention outcomes (Murden et al., 2008; Rasmussen, Lloyd, \& Wielandt, 2005). Since culture is an important part of the Occupational Therapy Practice Framework: Domain \& Process (Framework), occupational therapy educators have a duty to prepare future clinicians for culturally diverse clinical encounters (American Occupational Therapy Association [AOTA], 2014). Yet clear guidelines on how to most effectively teach cultural awareness and competency is still lacking. Educational research exploring pedagogies for teaching cultural awareness and competency is needed. The purpose of this study was to explore the impact of classroom instruction on cultural awareness and sensitivity on occupational therapy students.

\section{Culture and Cultural Competency}

The meaning of culture and cultural awareness must first be defined in order to understand the significance of cultural competency in occupational therapy education and practice. Culture is viewed as a broad concept and used as an inclusive term with no single, widely accepted definition in the literature (Rasmussen et al., 2005; Whiteford \& St-Clair, 2002). The concept of culture is learned, shared, and socially constructed (Cheung, Shah, \& Muncer, 2002; Humbert et al., 2012; Rasmussen et al., 2005). These learned and shared patterns include values, beliefs, customs, perceptions, history, politics, attitudes, lifestyles, emotions, and behaviors (Cheung et al., 2002; Humbert et al., 2012; Rasmussen et al., 2005). It is important to understand that these patterns of learned behavior are shared by members of a group, not an individual, and are not biological in nature (MacDonald, 1998). The AOTA does not define culture in the Framework (2014). However, the importance of the cultural context and how it impacts the individual's "identity and activity choices" is prevalent throughout the Framework (AOTA, 2014, p. S28).

Cultural competency is an awareness of, sensitivity to, and knowledge of the meaning of culture (Cheung et al., 2002; MacDonald, 1998; Murden et al., 2008). Whiteford and St-Clair (2002) further defined cultural competence as "the ability of a person to work effectively and negotiate successful outcomes with clients from differing cultural backgrounds than themselves" (p.130). Cultural competency is viewed as a set of cognitive, behavioral, and affective/motivational components (Abbe, Gulick, \& Herman, 2007). Rasmussen et al. (2005) explained that cultural competence can be developed by understanding the concept of culture, understanding one's perceptions of cultural issues, and the development of cultural awareness. Cultural awareness is having knowledge of different beliefs, traditions, roles and lifestyles, whereas cultural sensitivity is being open to and ready to respond to these differences (Cheung et al., 2002; Shah, 2016). This study explored the concepts of cultural awareness and sensitivity as a part of developing skills for occupational therapy students towards cultural competence. The development of cultural awareness provides the occupational therapist with the knowledge to develop the skills required to deliver quality care to diverse populations with sensitivity to cultural values, beliefs, and priorities that can affect an individual's health care (MacDonald, 1998; Mu et al., 2010; Munoz, 2007; Rasmussen et al., 2005). 


\section{Cultural Competency and Occupational Therapy Education}

Cultural awareness and competency becomes relevant when utilized to address the needs of culturally diverse client populations (Sood et al., 2014). Research has indicated that occupational therapy practitioners acknowledge the need to understand and develop cultural awareness and competency as a part of education and clinical practice (Cheung et al., 2002; Kale \& Hong, 2007; Mu et al., 2010; Munoz, 2007; Murden et al., 2008; Rasmussen et al., 2005; Whiteford \& St-Clair, 2002). Research shows that cultural awareness and competency are an evolving and developing process, yet continues to be "one of the least developed aspects of occupational therapy" (Awaad, 2003, p.358; Black \& Wells, 2007). The need to educate occupational therapy students to produce culturally competent therapists is also gaining recognition. The idea of cultural competence as a standard of care is reflected in the profession's educational objectives in the 2011 Accreditation Council for Occupational Therapy Education (ACOTE $\AA$ ) Standards and the Framework (ACOTE, 2012; AOTA, 2014; Murden et al., 2008). In the current ACOTE standards, the concept of culture and the cultural context can be found under foundational content, basic tenets, evaluation, and intervention (ACOTE, 2012).

The development of cultural competency helps ensure that students and therapists are prepared to recognize a client's personal experience within the cultural context (Sood et al., 2014). Occupational therapists must be aware and sensitive to cultural differences and must be able to consider cultural influences when selecting assessments and occupational interventions to meet the needs of their clients to improve quality of care and avoid any adverse impact (Cheung et al., 2002; Kale \& Hong, 2007; Murden et al., 2008; Sood et al., 2014). The inclusion of the concept of culture and the development of cultural awareness in the occupational therapy curriculum is necessary to prepare students for globalization and respond to the demands of today's culturally diverse work settings (Kale \& Hong, 2007; Mu et al., 2010).

The development of culturally sensitive practice begins with education. The importance of developing curriculum to promote cultural competency and the development of cultural awareness for occupational therapy students is emerging in the research literature. Recent literature has indicated that it is now the profession's obligation to educate its students to produce graduates who are culturally aware and sensitive to cultural differences in order to succeed in culturally diverse settings (Cheung et al., 2002; Rasmussen et al., 2005; Whiteford \& St-Clair, 2002). Rasmussen et al. (2005) reported that studies in the current occupational therapy literature focus attention on the idea of cultural awareness, sensitivity, and competence of occupational therapy practitioners. However, there is little consideration given to how occupational therapy students understand the concept of culture, students' perceptions of cultural issues, and the development of cultural awareness (Rasmussen et al., 2005). Research conducted to examine students' perceptions of cultural awareness has found that students acknowledged the impact of cultural differences on practice and self-identified as having limited knowledge and skills required to meet the needs of clients in multicultural practice (Cheung et al., 2002; Kale \& Hong, 2007; Rasmussen et al., 2005). The literature demonstrates that recent studies on the perceptions and development of 
cultural awareness and competency with occupational therapy students use existing tools that address the concepts of cultural awareness and sensitivity. Sood and colleagues (2014) used the Inventory for Assessing the Process of Cultural Competence Among Health Care Professionals Revised (IAPCC-R) developed by Campina-Bacote. While this tool offers a student version, it is not limited to occupational therapy practice. In research studies focused on occupational therapy students and education, the Cultural Awareness and Sensitivity Questionnaire (CASQ; Shah, 2016) was frequently cited (Cheung et al., 2002; Kale \& Hong, 2007; Murden et al., 2008; Rasmussen et al., 2005).

The incorporation of cultural training and experiences was the leading factor in developing cultural awareness and competency in occupational therapy students (Cheung et al., 2002; Rasmussen et al., 2005). In studies conducted to measure students' perceptions of their cultural awareness and competency, results indicated that the majority of students believed that cultural awareness was affected by education and fieldwork placement (Cheung et al., 2002; Kale \& Hong, 2007; Murden et al., 2008; Rasmussen et al., 2005). Murden et al. (2008) examined students' perceptions of cultural awareness and competency during their educational program. These researchers found that students desired a curriculum that exposed them to cultural experiences to develop their awareness and competency. Postgraduate students have also noted that the lack of education on cultural awareness and competency during the academic program limited their ability to appreciate cultural differences during fieldwork experience (Murden et al., 2008; Sood et al., 2014). Research has shown that while occupational therapy students perceived a lack of adequate cultural exposure during their education, they demonstrated a positive attitude towards education on cultural influences and developing an understanding of the importance of cultural differences (Cheung et al., 2002; Murden et al., 2008; Rasmussen et al., 2005).

The literature has revealed a gap in the cultural competence education for occupational therapy students and has demonstrated the importance of developing a culturally sensitive curriculum that will prepare students for today's work environment (Cheung et al., 2002; Mu et al., 2010; Rasmussen et al., 2005). Kale and Hong (2007) stated that this perceived lack of knowledge and skills demonstrates "the critical need to include issues of cultural sensitivity and awareness within the curriculum in order to equip students with the necessary skills required to work in a multicultural society" (p. 213). Kale and Hong (2007) also reported that cultural issues and instruction are often included in overall clinical experiences in the school program thus receiving minimal attention. In order to respond to the desire of students to become more culturally competent and to prepare therapists to succeed in culturally diverse settings, further research must be conducted to determine the best practices of cultural awareness and competency education.

\section{Purpose of Study}

The need to develop a curriculum that will produce graduates who are culturally aware and able to demonstrate culturally sensitive practice has been clearly demonstrated. In order to better understand how to incorporate issues of cultural sensitivity and 
awareness into occupational therapy education, this pilot study explored the effectiveness of classroom instruction on students' cultural awareness and ability to engage in culturally sensitive practice to promote cultural competence.

The current study explored the following research question: Is there a change in the level of cultural awareness and sensitivity in entry-level master's degree level occupational therapy students after classroom instruction on cultural awareness and culturally sensitive practice?

\section{METHODS}

\section{Research Design}

This pilot study used a quasi-experimental approach with a one group pretest-posttest design to explore the development of cultural awareness in occupational therapy students with classroom instruction on culturally sensitive practice. A one group pretestposttest design was selected because random assignment and/or use of a control group could be considered unethical with the study population and intervention (Portney \& Watkins, 2015). Specifically, withholding classroom instruction on cultural awareness and culturally sensitive practice from one group of students would be unethical.

\section{Participants}

The participants were a convenience sample of students in their first year of the master of occupational therapy program at Rockhurst University. A total of 45 students were recruited into the study. Students were recruited through a class presentation in their second semester of their first year prior to exposure to cultural education in other aspects of the curriculum. Students who were 19 years of age or older were included in this study. Students who had previously engaged in research of a similar nature resulting in prior experience with the CASQ (Shah, 2016) were excluded from the study.

\section{Instrument}

After a thorough literature review to determine existing tools for assessing cultural awareness and competency in occupational therapy, the authors selected the CASQ due to its use in other quantitative studies of this nature. The CASQ, a self-assessment questionnaire, was presented to students as an online survey. This questionnaire was developed and piloted by Cheung et al. (2002). The CASQ is a self-administered questionnaire consisting of three sections. The first section consists of demographic questions regarding the student's age, gender, and educational background. The second section has 10 statements (Table 1) on the student's perceptions of cultural awareness using the Likert-type five-point scale. Students were asked to indicate his or her response from the choices of strongly agree, agree, don't know, disagree, or strongly disagree. The third section has five questions (Table 2) that required the student to self-rate his or her perceived understanding and impact of cultural awareness including sources of information and access to services. This section was rated by the student using a continuum ranging from culturally "unaware" to "competent." The CASQ has internal consistency with a Cronbach's alpha of 0.69 (Murden et al., 2008). This number is considered to be close to an acceptable range of 0.70 to 0.95 (Tavakol \& Dennick, 2011). 


\section{Ethics}

The Institutional Review Boards at Creighton University and Rockhurst University approved this research. This research was conducted as part of a doctoral degree program of the authors. The authors recruited participants from a separate occupational therapy program to reduce bias. Approval from both Institutional Review Boards was obtained to ensure ethical research practices. Participants were advised that participation in the study and completion of the CASQ would help further research to contribute to the understanding of the effectiveness of classroom instruction on students' cultural awareness and ability to engage in culturally sensitive practice. Participants were instructed that participation in the study was voluntary and would have no impact on their course grade. All students provided informed consent prior to any data collection or classroom instruction on cultural awareness and culturally sensitive practice. All students participated in the classroom instruction regardless of participation in the research study.

\section{Procedure}

Students took the pre-test of the CASQ as an online survey 48 hours prior to completing classroom instruction on cultural awareness and culturally sensitive practice. Students then participated in the classroom instruction between pre-test and post-test data collection. Students were asked to complete the post-test CASQ within 48 hours of the completion of the classroom instruction.

Classroom instruction. The classroom instruction was provided through a one-day teaching module that was added as part of the course curriculum. This teaching module was based on best practices of teaching cultural awareness and sensitivity after review of literature on instructional methods. The teaching module was also developed with respect to the academic program's philosophy of integrating cultural education throughout the curriculum. This supports Black and Wells' (2007) concept that integration across the curriculum helped to promote ongoing analysis and critical awareness of the content. Due to the ongoing nature of cultural education within the curriculum, the authors chose to focus on cross-cultural communication in the teaching module. Cross-cultural communication was selected because students demonstrate cultural awareness through communication during the occupational therapy process (Purnell, 2009). Effective cross-cultural communication and subsequent cultural competence comes from students being aware and sensitive to the power of language (Black \& Wells, 2007).

The instruction utilized a combination of teaching and learning activities including lecture, discussion, case-based instruction, and role-playing simulation. The module included a short lecture to ensure students were prepared to address the issues of cross-cultural communication and understood the impact of cultural awareness and sensitivity in occupational therapy practice. Students engaged in small group work that developed skills to research various cultural backgrounds and applied this knowledge to case studies. Students then actively participated in a cross-cultural communication activity to simulate various cultural communication styles. The teaching module was developed and implemented by the first author of this study with approval from the 
instructor of the course curriculum. Prior to implementation, an expert in instructional methods in occupational therapy further reviewed the teaching module to ensure its pedagogical quality prior to implementation.

\section{Data Analysis}

Data analysis was performed on the pre-test and post-test scores obtained from the CASQ. The quantitative data was entered and analyzed using IBM SPSS Statistics for Windows, Version 24.0. The Wilcoxon signed-rank test was performed on all 15 survey questions to determine whether, if any, difference between the pre-test and post-test scores was statistically significant (Laerd Statistics, 2015). Portney and Watkins (2015) suggest the use of Wilcoxon signed-rank test for a one group pretest-posttest design when ordinal data and/or small sample sizes are used. The Wilcoxon signed-rank test is considered to be the nonparametric equivalent of the t-test for paired comparisons (Laerd Statistics, 2015; Portney \& Watkins, 2015). For the purpose of data analysis, the researchers applied numerical values to the responses of the CASQ pre-test and posttests for clarity in data analysis. The quantitative data from the CASQ was coded as the following: the 10 statements in Table 1 include strongly agree $=5$, agree $=4$, don't know $=3$, disagree $=2$, or strongly disagree $=1$ and the five questions in Table 2 include "am unaware" $=1$, "have limited awareness" $=2$, "have higher level of awareness" $=3$ and "feel competent" = 4 (Shah, 2016).

\section{RESULTS}

Forty-five students provided consent to participate in the study and completed both the pre-test and post-test of the online CASQ survey which was 100\% of the sample recruited for the study. Two survey responses were removed from the data set due to the study exclusion criteria and missing data resulting in a final sample of 43 students. The majority of the students were aged $18-24$ years $(n=40)$ and the remaining students were aged 25-30 years $(n=3)$. Most respondents were female $(n=40)$ with three males included in this study. All students were in their second semester of the first year of the entry-level master of occupational therapy program. 
Table 1

Responses to Students' Perceptions of Cultural Awareness

\begin{tabular}{|l|c|c|c|c|}
\hline \multicolumn{1}{|c|}{ Statement } & $\begin{array}{c}\text { Pre-Test } \\
\text { Mean }\end{array}$ & $\begin{array}{c}\text { Post-Test } \\
\text { Mean }\end{array}$ & Z Score & Significance \\
\hline $\begin{array}{l}\text { 1. There is a growing demand of } \\
\text { occupational therapy services from } \\
\text { ethnic minorities. }\end{array}$ & 3.84 & 4.67 & -4.156 & $<.001^{*}$ \\
\hline $\begin{array}{l}\text { 2. Cultural factors could influence } \\
\text { client's occupational performance. }\end{array}$ & 4.70 & 4.98 & -3.464 & $.001^{*}$ \\
\hline $\begin{array}{l}\text { 3. Cultural factors should be } \\
\text { considered in occupational therapy } \\
\text { process. }\end{array}$ & 4.88 & 4.95 & -1.134 & .257 \\
\hline $\begin{array}{l}\text { 4. Overlooking cultural influences } \\
\text { could affect occupational therapy } \\
\text { assessment. }\end{array}$ & 4.63 & 4.91 & -2.683 & $.007^{*}$ \\
\hline $\begin{array}{l}\text { 5. Overlooking cultural influences } \\
\text { could affect the outcome of the } \\
\text { intervention. }\end{array}$ & 4.53 & 4.93 & -3.545 & $<.001^{*}$ \\
\hline $\begin{array}{l}\text { 6. Students often have limited } \\
\text { knowledge about different cultures. }\end{array}$ & 3.91 & 4.09 & -1.237 & .216 \\
\hline $\begin{array}{l}\text { 7. The level of cultural awareness } \\
\text { could be effected by classroom } \\
\text { education. }\end{array}$ & 4.30 & 4.56 & -2.294 & $.022^{*}$ \\
\hline $\begin{array}{l}\text { 8. The level of cultural awareness } \\
\text { could be effected by fieldwork } \\
\text { experiences. }\end{array}$ & 4.37 & 4.67 & -2.268 & $.023^{*}$ \\
\hline $\begin{array}{l}\text { 9. Should there be an adequate } \\
\text { exposure to cultural awareness in } \\
\text { occupational therapy program. }\end{array}$ & 4.33 & 4.79 & -3.507 & $<.001^{*}$ \\
\hline $\begin{array}{l}\text { 10. Should there be an adequate } \\
\text { exposure to cultural awareness in } \\
\text { fieldwork experiences. }\end{array}$ & 4.33 & 4.79 & -3.651 & $<.001^{*}$ \\
\hline
\end{tabular}

Note. Significant findings include an asterisk $(\mathrm{p}<.05)$.

Questions in column 1 are from the Cultural Awareness and Sensitivity Questionnaire CASQ) by S. Shah (Unpublished instrument). Printed with permission from S. Shah. 
Table 2

Responses to Students' Perceived Understanding and Impact of Cultural Awareness

\begin{tabular}{|l|c|c|c|c|}
\hline \multicolumn{1}{|c|}{ Question } & $\begin{array}{c}\text { Pre-Test } \\
\text { Mean }\end{array}$ & $\begin{array}{c}\text { Post-Test } \\
\text { Mean }\end{array}$ & Z Score & Significance \\
\hline $\begin{array}{l}\text { 1. How aware are you of the } \\
\text { impact of cultural background on a } \\
\text { person's belief, attitude, behavior, } \\
\text { and lifestyle? }\end{array}$ & 2.93 & 3.33 & -2.229 & $.026^{*}$ \\
\hline $\begin{array}{l}\text { 2. How aware are you of different } \\
\text { cultural factors which could affect } \\
\text { occupational therapy services? }\end{array}$ & 2.67 & 3.35 & -3.675 & $<.001^{*}$ \\
\hline $\begin{array}{l}\text { 3. How aware are you of the } \\
\text { sources of information such as } \\
\text { books, or leaflets, or websites } \\
\text { about different cultures? }\end{array}$ & 2.16 & 3.05 & -3.814 & $<.001^{*}$ \\
\hline $\begin{array}{l}\text { 4. How aware are you of access to } \\
\text { translation services? }\end{array}$ & 1.56 & 2.28 & -3.483 & $<.001^{*}$ \\
\hline $\begin{array}{l}\text { 5. How aware are you of methods } \\
\text { to reduce cultural barriers? }\end{array}$ & 2.07 & 3.09 & -4.536 & $<.001^{*}$ \\
\hline
\end{tabular}

Note. Significant findings include an asterisk $(\mathrm{p}<.05)$. Questions in column 1 are from the Cultural Awareness and Sensitivity Questionnaire CASQ) by S. Shah (Unpublished instrument). Printed with permission from S. Shah.

Results from the Wilcoxon-signed rank test indicated a change in the students' level of cultural awareness and sensitivity after classroom instruction. Overall, the questions addressed in Table 1 showed a change in students' perceptions of cultural awareness. All questions in Table 1 showed a significant level of change $(p<.05)$ with exception of questions three and six. All of the questions in Table 2 showed a significant level of change $(p<.05)$ between pre-test and post-test means in students' perceived understanding and impact of cultural awareness.

\section{DISCUSSION}

The findings of this study suggested that classroom instruction on cross-cultural communication can change the level of students' cultural awareness and sensitivity. Comparison of the pre-test and post-test scores of the CASQ indicated that students who completed the classroom instruction demonstrated an overall improvement with students' perceptions of cultural awareness and perceived understanding and impact of cultural awareness. Increased cultural awareness will allow students to better understand the interactions between culture and occupation and to incorporate culturally sensitive practices into future service delivery (Murden et al., 2008; Rasmussen et al., 2005; Whiteford \& St-Clair, 2002).

The students improved in their recognition that there is a growing demand for occupational therapy services from ethnic minorities (Statement $1, p<.001$ ). The students demonstrated an improved understanding of the impact of cultural influences 
on the delivery of occupational therapy services in statements 2,4 , and 5 . The pre-test and post-test scores indicated no statistically significant change in students' understanding that cultural factors should be considered in occupational therapy process (Statement 3). This suggests that the classroom instruction allowed the students to acknowledge the importance of cultural factors in the occupational therapy process and the instruction changed the perception of cultural influence on the different aspects including occupational performance, assessment, intervention, and outcomes. The students demonstrated a positive change in their beliefs' regarding cultural awareness education in statements 7-10. Students recognized the effect and need for cultural awareness education across the curriculum including classroom instruction and fieldwork experiences. The results are supported by Black and Wells (2007) who state that cultural education should be integrated throughout the curriculum. All of the questions in the final section of the CASQ indicated a statistically significant increase from pre-test to post-test scores. This indicated that classroom instruction improved the students' level of cultural awareness including "their knowledge of the impact of cultural factors, sources of information, and access to relevant services" (Cheung et al., 2002, p. 545). The use of a combination of teaching and learning activities allowed students' understanding of the cultural awareness education to be reinforced.

Every clinical encounter is influenced by culture as occupational therapy practitioners are working in increasingly culturally diverse settings (Cheung et al., 2002; Munoz, 2007; Purnell, 2009; Simonelis, Njelesani, Novak, Kuzma, \& Cameron, 2011). Due to this increasing diversity, the need for cultural awareness and sensitive practice must be addressed by occupational therapy practitioners (Murden et al., 2008). This study contributes to the growing body of literature comparing pre-test and post-test scores from cultural awareness assessments. These results are supported by the educational pedagogy that cultural education must allow students to be "active participants in the learning process" (Black \& Wells, 2007, p. 278). The significant change seen after the one-day teaching module suggests that teaching methods that include active participation can be effective means for educating students on cultural awareness and sensitivity (Black \& Wells, 2007). Occupational therapy students need the opportunity to actively engage with the concepts of cultural awareness and sensitivity to feel prepared for clinical practice. This active participation allowed the students to apply meaning to the concepts presented during the teaching module to future clinical encounters. This study contributes to the growing evidence for pedagogical approaches for the instruction and training that is critical to prepare future practitioners to handle the demands of clinical practice.

\section{Limitations}

This study used a convenience sample of students from Rockhurst University. The sample was small and consisted of students of similar ages and were mostly female. The small sample size limits the generalizability to occupational therapy programs across the United States. However, the demographics of the study with mostly female participants is consistent with the current demographics of the profession. The United States Department of Labor (2017) reports that in 2016, 89.2\% of occupational therapists are women. Due to ethical standards, the teaching module was offered to all 
students and randomization did not occur. This could further limit the confidence of the effectiveness of the teaching module. An additional limitation of this study was the instrument utilized for the pretest-posttest comparison. The CASQ was a selfassessment tool that only measured perceptions of cultural awareness and sensitivity. An objective measure of cultural awareness and sensitivity would provide a new level of effectiveness to the study of cultural awareness education.

\section{Recommendations for Future Research}

Based on a review of the current literature and the results of this study, there is a need to continue research on education practices to fully develop a curriculum for cultural awareness and sensitivity. The results of this study indicate that cultural awareness and sensitivity are impacted through classroom instruction. Further research should explore how this impact can be seen across the curriculum in both the classroom and clinical experiences. This research should include the impact of fieldwork education on cultural awareness and sensitivity as well as the impact of classroom instruction combined with fieldwork education on cultural awareness and sensitivity. The results would be strengthened by the inclusion of a variety of occupational therapy programs with a wider demographic of students. A multi-program study would allow for the use of control groups without the ethical concerns. Research should also allow more time between pre-test, instruction, and post-test to reduce carryover effect. To explore the impact of cultural instruction and experiences over time, administration of the CASQ after clinical experiences should be explored. In addition, longitudinal studies, which follow students through the occupational therapy curriculum, will enhance the understanding of the development of cultural awareness and sensitivity over time. Future research should also include assessment of the cognitive, behavioral, and affective/motivational components of cultural competency.

\section{CONCLUSION}

This study contributes to the growing body of literature and helps fill the gap surrounding cultural awareness and sensitivity in occupational therapy education and literature. The authors intend for this pilot study to lead to further research on the teaching and learning strategies needed to develop a curriculum that will produce graduates who are culturally aware and are able to demonstrate culturally sensitive practice. This education will contribute to the development of cultural competence allowing future occupational therapy practitioners to provide quality care in diverse settings.

\section{References}

Abbe, A., Gulick, L. M., \& Herman, J. L. (2007). Cross-cultural competence in Army leaders: A conceptual and empirical foundation. Arlington, VA: US Army Research Institute for the Behavioral and Social Sciences.

Accreditation Council for Occupational Therapy Education. (2012). 2011 Accreditation Council for Occupational Therapy Education (ACOTE) standards. American Journal of Occupational Therapy, 66, S6-S74. https://doi.org/10.5014/ajot.2012.66S6 
American Occupational Therapy Association. (2014). Occupational therapy practice framework: Domain \& process ( $3^{\text {rd }}$ ed.). American Journal of Occupational Therapy, 68 (Suppl. 1), S1-S48. https://doi.org/10.5014/ajot.2014.682006

Awaad, J. (2003). Culture, cultural competency and occupational therapy: A review of the literature. British Journal of Occupational Therapy, 66(8), 356-362. https://doi.org/10.1177/030802260306600804

Black, R. M., \& Wells, S. A. (2007). Culture and occupation: A model of empowerment in occupational therapy. Bethesda, MD: AOTA Press.

Cheung, Y., Shah, S., \& Muncer, S. (2002). An exploratory investigation of undergraduate students' perceptions of cultural awareness. British Journal of Occupational Therapy, 65(12), 543-550. https://doi.org/10.1177/030802260206501203

Humbert, T. K., Burket, A., Deveney, R., \& Kennedy, K. (2012). Occupational therapy students' perspectives regarding international cross-cultural experiences. Australian Occupational Therapy Journal, 59(3), 225-234. https://doi.org/10.1111/j.1440-1630.2011.00987.x

IBM Corp. Released 2016. IBM SPSS Statistics for Windows (Version 24.0) [Computer software]. Armonk, NY: IBM Corp.

Kale, S., \& Hong, C. S. (2007). An investigation of therapy student's perceptions of cultural awareness. International Journal of Therapy \& Rehabilitation, 14(5), 210214. https://doi.org/10.12968/ijtr.2007.14.5.23538

Laerd Statistics (2015). Wilcoxon signed-rank test using SPSS Statistics. Statistical tutorials and software guides. Retrieved from https://statistics.laerd.com/

MacDonald, R. (1998). What is cultural competency? British Journal of Occupational Therapy, 61(7), 325-328. https://doi.org/10.1177/030802269806100709

Masin, H. L. (2011). Communicating with cultural sensitivity. In Davis, C. M.(Ed.), Patient practitioner interaction: An experiential manual for developing the art of health care (pp.143-158). Thorofare, NJ: Slack Incorporated.

Mu, K., Coppard, B. M., Bracciano, A., Doll, J., \& Matthews, A. (2010). Fostering cultural competency, clinical reasoning, and leadership through international outreach. Occupational Therapy in Health Care, 24(1), 74-85. https://doi.org/10.3109/07380570903329628

Munoz, J. P. (2007). Culturally responsive caring in occupational therapy. Occupational Therapy International, 14(4), 256-280. https://doi.org/10.1002/oti.238

Murden, R., Norman, A., Ross, J., Sturdivant, E., Kedia, M., \& Shah, S. (2008). Occupational therapy students' perceptions of their cultural awareness and competency. Occupational Therapy International, 15(3), 191-203. https://doi.org/10.1002/oti.253

Portney, L. G., \& Watkins, M. P. (2015). Foundations of clinical research: Applications to practice (3rd ed.). Philadelpha, PA: F. A. Davis Company.

Purnell, L. D. (2009). Guide to culturally competent health care. (2nd ed.) Philadelphia: FA Davis.

Rasmussen, T. M., Lloyd, C., \& Wielandt, T. (2005). Cultural awareness among Queensland undergraduate occupational therapy students. Australian Occupational Therapy Journal, 52(4), 302-310. https://doi.org/10.1111/j.1440-1630.2005.00508.x 
Shah, S. (2016). Cultural Awareness and Sensitivity Questionnaire. Unpublished instrument.

Simonelis, J., Njelesani, J., Novak, L., Kuzma, C., \& Cameron, D. (2011). International fieldwork placements and occupational therapy: lived experiences of the major stakeholders. Australian Occupational Therapy Journal, 58(5), 370-377. https://doi.org/10.1111/j.1440-1630.2011.00942.x

Sood, D., Cepa, D., Dsouza, S. A., Saha, S., Aikat, R., \& Tuuk, A. (2014). Impact of international collaborative project on cultural competence among occupational therapy students. Open Journal of Occupational Therapy, 2(3), Article 7. https://doi.org/10.15453/2168-6408.1111

Tavakol, M., \& Dennick, R. (2011). Making sense of Cronbach's alpha. International Journal of Medical Education, 2, 53-55. https://doi.org/10.5116/ijme.4dfb.8dfd

United States Department of Labor. (2017, February 8). Labor force statistics from the current population survey. Retrieved from https://www.bls.gov/cps/cpsaat11.htm

Whiteford, G., \& St-Clair, V. W. (2002). Being prepared for diversity in practice: Occupational therapy students' perceptions of valuable intercultural learning experiences. British Journal of Occupational Therapy, 65(3), 129-137. https://doi.org/10.1177/030802260206500305 